Enclaves. Revista de Literatura, Música y Artes Escénicas, n. ${ }^{\circ}$ 1, 2021, pp. 125-143. eISSN 2792-7350

\title{
DE LA LITERATURA A LA ESCENA. DESCRIPCIÓN DE UN PROCESO CREATIVO PERSONAL A PARTIR DEL ESPECTÁCULO LA MUJER Y EL PELELE DE LA COMPAÑÍA ISABEL BAYÓN
}

\author{
Isabel Bayón Gamero \\ CSDMA
}

Fecha de recepción: 18/11/2020

Fecha de aceptación: 02/06/2021

\section{Resumen}

Este texto tiene la intención de mostrar, siempre bajo el prisma de la investigación artística, las diferentes etapas, los procesos de elaboración, la vinculación y la justificación entre elementos que pueden constituir el propósito de llevar una obra literaria al escenario; en este caso, utilizando el flamenco como lenguaje escénico. Es una ventana donde se muestran los ingredientes que pueden estar presentes dentro de un proceso creativo. El planteamiento se conforma como una propuesta de análisis, donde se refiere cómo fue el proceso de creación de un espectáculo en cuanto a la justificación y adaptación argumental, el planteamiento coreográfico, la propuesta musical y la dirección escénica.

Se pretende contar qué elementos fueron necesarios y cómo estos van marcando y delimitando las distintas vías que confluyen en el camino de la creación. Así pues, este estudio radica en un trabajo basado en el análisis y la observación de un proceso personal, dentro de un marco particular.

Para ello, he tomado como ejemplo práctico el espectáculo La mujer y el pelele, título homónimo de la novela del escritor francés Pierre Louÿs, en la que está basado. La adaptación de la novela se desarrolla en clave flamenca, mostrando un modelo particular del arquetipo, ya mitémico, de la femme fatale. La obra fue estrenada en el 2004 por la compañía de Isabel Bayón en la XIII Bienal de Flamenco de Sevilla, con la dramaturgia de Antonio Álamo y bajo la dirección escénica de Pepa Gamboa.

Palabras clave: Mujer fatal, baile flamenco, mito, escena, coreografía, literatura, composición.

FROM LITERATURE TO STAGE.

DESCRIPTION OF A PERSONAL CREATIVE PROCESS BASED ON THE SHOW LA MUJER Y EL PELELE BY ISABEL BAYÓN COMPANY

\begin{abstract}
Under the prism of the artistic research, this text intends to show the different stages, the creation processes, the connection and the justification between elements that may
\end{abstract}


constitute the purpose of bringing a literary work to the stage; in this case, using flamenco as a scenic language. This contribution is a window where the ingredients that may be present within a creative process are shown. The approach is formed as a proposal for analysis, where it refers to how the process of creating a show was in terms of the justification and plot adaptation, the choreographic approach, the musical proposal and the stage direction.

This work contains a description of the elements that lead to and define the different paths which converge on every creation process. It is, therefore, the result of a personal analysis and observation process within a specific framework. It is intended to tell what elements were necessary and how they are marking and delimiting the different paths that converge on the path of creation. Thus, this study is based on a work based on the analysis and observation of a personal process, within a particular framework.

To do this, I have taken as a practical example the show La mujer y el pelele, the homonymous title of the novel by the French writer Pierre Louÿs, on which it is based. The adaptation of the novel takes place in a flamenco key, showing a particular model of the archetype, already mythemical, of the femme fatale. The show was premiered in 2004 by Isabel Bayón Company at the $13^{\text {th }}$ Seville Flamenco Biennial, with the theatrical adaptation of Antonio Álamo and under the stage direction of Pepa Gamboa.

Keywords: Femme fatale, Flamenco dance, Myth, Scene, Choreography, Literature, Composition.

\section{Sumario}

1. Introducción 126

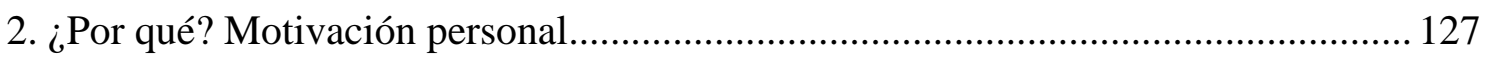

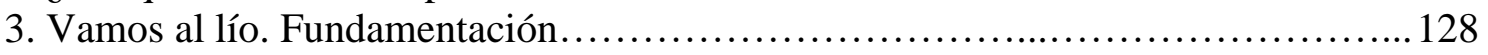

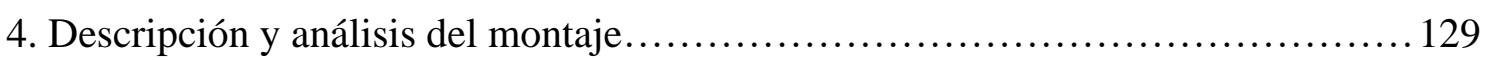

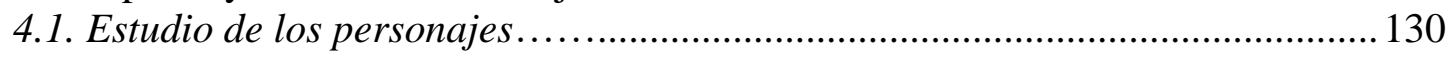

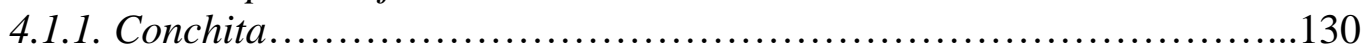

4.1.2. Don Mateo..................................................... 130

4.1.3. El ciego.......................................................131

4.1.4. Morenito........................................................ 131

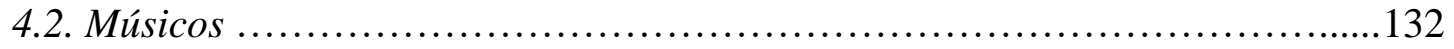

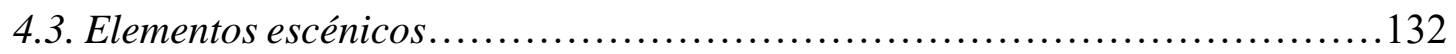

5. Proceso de creación coreográfica.......................................... 133

5.1. Argumentación coreográfica / Justificación de los palos flamencos............133

5.2. Proceso coreográfico / Pautas generales.......................................140

6. Reflexión a posteriori................................................. 143

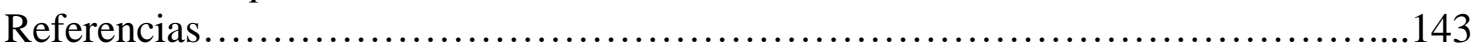

\section{Introducción}

Normalmente, los artistas llevamos a cabo un tipo de trabajo que tiene mucho de interioridades y de secretos casi inconfesables. Sin embargo, paradójicamente, estos 
cobran sentido cuando son compartidos, ya que esa es su finalidad: la de entregarse y ser objeto de la mirada y escrutinio del público; mientras más público, mejor.

Todos y cada uno de nosotros tiene su alfar, su cocina; ese lugar donde se conjugan maneras, elementos e ingredientes con los que invocar a las musas. En una suerte de proceso de laboratorio, el artista casi siempre pretende encontrar la manera de convertir una ilusión, un deseo de contar algo, o si se me permite algo un poco menos prosaico, la necesidad de trabajar en un resultado que tenga algo que ofrecer al espectador, algo con lo que emocionar y, como en general el artista no está libre de vanidad, algo que procure quedar en la memoria del que asiste.

Este es un acto de confesión que pretende compartir un proceso de interioridades que busca el escaparate. Las distintas piezas que intervienen en la formación de un espectáculo se unen en un engranaje que funciona de forma sincrónica. Bien es verdad que no todas las maquinarias logran tener un buen funcionamiento, ya que además de los elementos humanos que buscan la expresión y la comunicación, han de intervenir otros que dependen de las administraciones y de los gestores de la cultura, y ahí, a veces, como dice la canción, todas las cosas no son como parecen. Realizaremos, para ello, una doble aproximación metodológica: por un lado, el estudio de caso; por otro, el análisis de contenido.

Volviendo a la razón principal de esta exposición:

\section{2. ¿Por qué? Motivación personal}

El proceso de la creación artística oculta todo un mundo de experiencias, siendo múltiples los ángulos desde donde poder realizar un estudio. La creación, sus mecanismos, las razones, lo motívico, la inspiración, lo puramente artístico, los instrumentos de manifestación, las herramientas y sus reglas, etc., son variables que entran en juego a la hora de realizar una operación donde la aplicación de la matemática no siempre garantiza el resultado previsto. Pretender, en unas pocas páginas, contar una labor de investigación que abarque todas esas posibilidades se perfilaría como una empresa de compleja factura. Es por eso que quiero poner énfasis en la cabecera del escrito, sobre todo porque me servirá para delimitar y, de paso, ayudar a una mejor comprensión de los contenidos que intentaré desarrollar. Bajo este título, se plantean procesos que pertenecen sobre todo al plano de la investigación artística, y es bajo ese prisma con el que los considero y expongo.

Este trabajo tiene como punto de partida el hecho de haber llevado a cabo una adaptación entre la novela de Pierre Louÿs, La mujer y el pelele (1896), y el mundo del flamenco. La aproximación a esta novela, cuyo provocador argumento sobre Conchita Pérez, la joven seductora del desocupado y rico don Mateo - se inscribe en el mito de la femme fatale-, se hizo a través de una propuesta teatral y coreográfica en la que se integraron una adaptación dramática y los elementos clásicos que conforman la unidad flamenca básica: el cante, el toque y el baile.

La experiencia que el hecho de protagonizar y realizar aquella propuesta flamenca me proporcionó me ha servido de excusa para realizar este trabajo de investigación, basado en un análisis personal. Con todo esto, quiero sentirme espectadora de mi propio proceso creativo, tomando en consecuencia una actitud crítica ante lo realizado. 
Enclaves. Revista de Literatura, Música y Artes Escénicas, n. ${ }^{\circ}$ 1, 2021, pp. 125-143. eISSN 2792-7350

Isabel Bayón Gamero, «De la literatura a la escena. Descripción

Quiero aprovechar estas líneas para agradecerle a Pepa Gamboa no solo la ocurrencia, sino que además pensara en mí para otorgarle a Concepción Pérez, Concha, Conchita, el don de bailar flamenco.

\section{Vamos al lío. Fundamentación}

El flamenco puede entenderse como un universo con unas líneas estéticas y de contenido bien delimitadas y definidas. Pero, lejos de concebirse como algo cerrado o impermeable, ha quedado demostrado que es una manifestación que admite la integración de otras disciplinas como el teatro, el cine, otros estilos de danza, etc., reflejándose como un arte versátil y heterogéneo en el que la obra escénica toma cuerpo en el «actor contemporáneo», que ya no es un imitador mímico, un simulador, sino que performa por sí mismo y no tiene porqué replicar la realidad de forma global o mimética en la figura del personaje (Pavis, 5).

Para esta adaptación, se vio que el punto de partida expuesto en la novela se mostraba idóneo para que el lenguaje y la textura flamenca fueran no solo excusa, sino y sobre todo, parte protagonista. Pierre Louÿs nos presenta una Sevilla finisecular decimonónica, con Conchita, una protagonista que se busca la vida, entre otras cosas, como bailaora... Es principalmente a través de su personaje donde se encarna el prototipo de mujer sensual y erótica, de una Carmen, de una Mata Hari, que nos da la oportunidad de enfocar la mirada hacia el estereotipo de mujer fatal.

Una correcta documentación es sin duda imprescindible para llevar a cabo un montaje de estas características. Así pues, el libro de Goujon y Camero (760-763) me ayudó a entender los vínculos de Loüys con la Andalucía de finales del XIX. A partir de este estudio planteado por los autores, podemos llegar a la conclusión de que, aunque tanto el modelo femenino como el marco contextual donde tiene lugar la historia se prestan a ser tratados bajo una estética costumbrista, no es en la novela La mujer y el pelele donde se plantea esa opción. En ella vemos un discurso alejado del subjetivismo propio del romanticismo, del exotismo y del costumbrismo. Prescindiendo de ese enfoque, encontramos cómo el autor se adentra en el mundo de las pasiones, proyectando casi una lucha de géneros donde el deseo se convierte en motor para lograr lo que se persigue.

Otra fuente de documentación importante fueron las películas. Son innumerables los filmes que están basados en obras literarias. También lo son las adaptaciones de estas, tanto a la pequeña como a la gran pantalla. En esta ocasión puse atención en Cet obscure objet du désir, de Luis Buñuel de 1977, y La mujer y el pelele, del director Mario Camus del año 1990. Es instructivo ver cómo los directores y actores tratan el tema, cómo lo plantean y desarrollan teniendo en cuenta lo complejo que es hacer una adaptación literaria. Fue inspirador, para meterme en el papel, el contemplar ese modelo de mujer que instrumentaliza su cuerpo y poder de seducción para conseguir un propósito determinado.

Siguiendo con la búsqueda de documentación pertinente, me encontré con el ejemplo que nos dejara don Ramón María del Valle-Inclán, uno de los dramaturgos, poetas y novelistas más representativos de la generación del 98, que nos ofrece una posible definición del estereotipo de mujer fatal. Leemos de la obra de Valle Inclán el discurrir de la fijación pasional que ciega a Víctor por Paca la Gallarda. En su novela La cara de Dios podemos leer lo siguiente: 
Casi todos los hombres de tu temperamento tienen en la vida una mujer así. La mujer fatal es la que se ve una vez y se recuerda para siempre. Esas mujeres son desastres de los cuales quedan siempre vestigios en el cuerpo y en el alma. Hay hombres que se matan por ellas; otros que se extravían [...]. (273)

En la búsqueda de modelos que encajaran dentro del mito, encontré también ejemplos que han sido motivo de inspiración dentro del arte para pintores, escultores, músicos o escritores. Salomé, la mujer que corta la cabeza de Juan el Bautista, Pandora, la que liberó todos los males, Dalila, que derrotó a Sansón con su castración simbólica, o Lilit, la primera mujer a la que alude el Génesis. Todos estos son modelos de femme fatale y, por lo tanto, susceptibles de servir como «maestras» en la tarea de entender al personaje de Conchita.

\section{Descripción y análisis del montaje}

Para adentrarnos en la adaptación y dramaturgia creada por Antonio Álamo de la novela de Pierre Louÿs, centraremos primeramente la atención en los personajes principales, que vertebran y dan soporte argumental a la obra. Cada uno de ellos tiene una función y características únicas que se dibujan dentro de un entramado que se perfila con matices que unen lo hilarante con el drama. Todos estos personajes van tomando y alternando su protagonismo según la escena a representar.

Para hilar el tejido y hacer el engarce narrativo, tanto Antonio Álamo — dramaturgo - como Pepa Gamboa - directora - y yo nos servimos de diferentes herramientas que serían vitales para enfatizar el carácter y la funcionalidad que tiene esta adaptación, es decir, la de ser una representación teatral danzada. Entre estas herramientas están, por supuesto, los tres elementos que de forma tradicional conforman la alineación natural del flamenco: el cante, la guitarra y el baile.

Como apoyo a este modelo narrativo, también se utilizan personajes que no están ligados a la estética propia del flamenco, pero que, dentro del contexto, van a llegar a aflamencarse y hacer la función — como en el caso del «ciego»— de bisagra temporal a través de momentos de la acción en los que, en un falso standby, servirán como voz en off del protagonista masculino, don Mateo. Todos los elementos y personajes que intervienen en el devenir narrativo están supeditados a las necesidades de la dramaturgia.

El cante va a usar letras que en todo momento apoyarán el discurso escénico, certificando lo que sucede en la escena, bien de manera directa y con una lírica gráfica, bien de forma más indirecta, utilizando letras que apoyarán el momento con un tipo de mensaje más simbólico o filosófico. Hay que remarcar la capacidad de síntesis que existe en la lírica flamenca, capaz de albergar en unas pocas líneas grandes verdades. Las letras, a modo de microescritos, tienen la capacidad de sintetizar, en un breve espacio, emociones, pensamientos, formas de vida e incluso cuestiones existenciales y urbanofilosóficas.

De igual manera, la música servirá para subrayar con cadencias sonoras todos los estados anímicos, los mensajes cantados, así como el mundo vivencial de Conchita, que se materializa y manifiesta en movimiento a través del baile flamenco. 
Enclaves. Revista de Literatura, Música y Artes Escénicas, n. ${ }^{\circ}$ 1, 2021, pp. 125-143. eISSN 2792-7350

Isabel Bayón Gamero, «De la literatura a la escena. Descripción

Compañía Isabel Bayón», https://dx.doi.org/10.12795/enclaves.2021.i01.08

\subsection{Estudio de los personajes}

\subsubsection{Conchita}

Concepción Pérez, Concha, Conchita, ¿hablamos de la misma, no?... ${ }^{1}$

Personaje principal femenino que se instala en la obsesión de don Mateo. Su perfil de mujer fatal no es nuevo. En ocasiones, es un reflejo o réplica, con algunas diferencias, de otros modelos, aunque en lo estructural del concepto es similar a personajes como la Carmen de Merimée y Bizet o la nínfula Lulú de Nabokov.

Conchita es un depredador más de ese ecosistema social que se dibuja en la Sevilla de finales de siglo, donde la picaresca y la necesidad hacen que surjan personajes que pretendan el engaño como «recurso laboral». Ella seduce, tiraniza y sablea a don Mateo a cambio de ciertos consentimientos de corte sexual que no llegan a consumarse. En la novela, y no en la adaptación, don Mateo llega hasta el punto de doblegar y poseer a Conchita después de una paliza.

En la dramaturgia hecha por Antonio Álamo y dirigida por Pepa Gamboa, Conchita hilará una suerte de bailes que darán razón y sentido flamenco a las escenas.

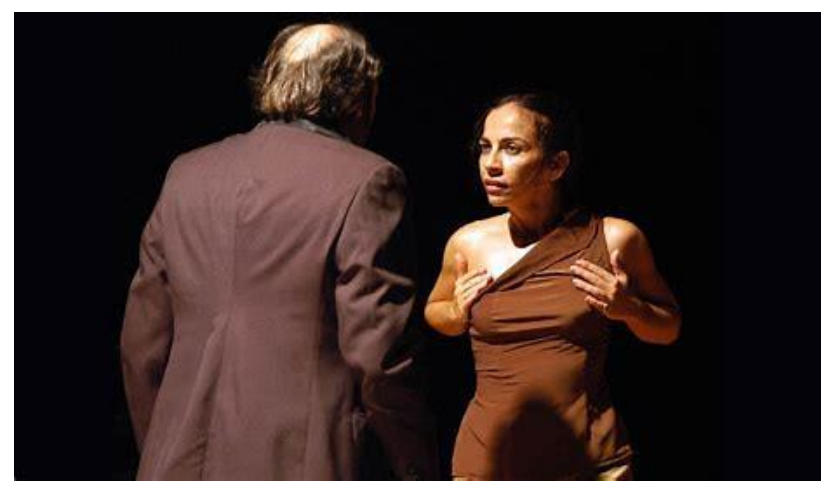

La mujer y el pelele.

Fuente: https://www.isabelbayon.es/?portfolio-item=la-mujer-y-el-pelele

\subsubsection{Don Mateo}

¡Juro, juro que, desde hoy hasta el día de mi muerte, no se me volverá a ver con mujer alguna!, ¡lo juro!, ¡lo juro!, ¡lo juro...

Es una reproducción de $E l$ pelele, el personaje manteado por un grupo de mujeres y representado en el famoso cuadro de finales del XVIII firmado por Francisco de Goya. En este caso, sometido por una sola mujer, el pelele es un adinerado cuarentón de clase social, resuelta víctima de su propia precariedad sentimental y esclavo casi patológico de su deseo.

Don Mateo podría servirnos para encarnar el razonamiento que arguye la poca voluntad del hombre frente a los placeres carnales, hasta el punto de que se anule la razón y que sucumba ante la oferta de consumar un deseo que priva del sentido y la racionalidad.

\footnotetext{
${ }^{1}$ Parte del texto confeccionado por Antonio Álamo para el guion dramático.
} 
Enclaves. Revista de Literatura, Música y Artes Escénicas, n.o 1, 2021, pp. 125-143. eISSN 2792-7350

Isabel Bayón Gamero, «De la literatura a la escena. Descripción

Un don Mateo representado por el actor Juan Motilla resolverá su devenir en una historia que se desarrolla mediante escenas en las que será protagonista y coautor de su propio desastre.

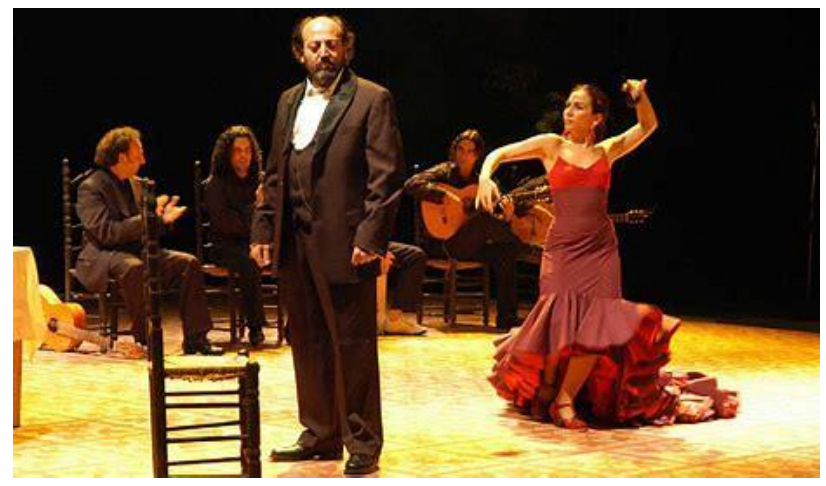

La mujer y el pelele.

Fuente: https://www.isabelbayon.es/?portfolio-item=la-mujer-y-el-pelele

\subsubsection{El ciego}

La mujer, como la gata, es de quien la ata...

Este es un personaje que no aparece en la novela de Louÿs. Fruto de la intuición creativa de Pepa Gamboa y Antonio Álamo, viene a servirnos de instrumento narrador, en ocasiones del discurso interior de don Mateo y, en otras, como pregonero musical de la escena que ha de venir o que acaba de terminar. Personaje cómico en su concepto argumental que respalda su funcionalidad y uso en una base histórica que se manifestó entre los siglos XV a XIX a través de los romances de ciego y los pliegos de cordel.

Su función social fue evidente, ya que tuvo gran importancia como uno de los medios más frecuentes de difusión de la lírica del Cancionero y del Romancero, así como en las narraciones de aventuras. La aparición de este ciego propone un aire que en ocasiones es jocoso y que en otras lleva un regusto amargo, en cuanto que pone en voz alta el desasosiego mental de un Mateo que ha perdido el norte.

Es el cantaor Juan José Amador quien da vida al personaje, haciendo uso de su voz como herramienta para advertirnos de lo que en la escena se representa. Será Pepa Gamboa la que sitúe y oriente al personaje dentro del devenir escénico. Su discurso comunicativo se plantea mediante sutiles gags, producto de la creatividad e intuición de la directora.

\subsubsection{Morenito}

Cómo has tenío el valor de echarte un amante nuevo estando en el mundo yo...

El artista de flamenco-pop Tomasito encarna la figura del morenito, que es, en este caso, el amante de Conchita. Sirve como un elemento más para consolidar el tormento que don Mateo padece. La novela muestra así, y de manera indirecta, un retrato de esa comunidad de chulos, tahúres, impostores y canallas que muestran la decadencia y la degradación de una sociedad que intenta sobrevivir a costa del que se deja engañar. 
Enclaves. Revista de Literatura, Música y Artes Escénicas, n. o 1, 2021, pp. 125-143. eISSN 2792-7350

Isabel Bayón Gamero, «De la literatura a la escena. Descripción

\subsection{Músicos}

Rosario de la aurora. Los campanilleros. Pasa una procesión lúgubre con campanas....

Campanilleros de ánimas benditas

-Frailes, con farol y campanilla-

- ¡Ave María purísima!

- Sin pecado concebida...

- Toque de campanilla-.

Los músicos no conforman un personaje dentro de la dramaturgia, pero sí son usados más allá de la funcionalidad musical que obviamente tienen dentro de la representación, como un elemento que sirve de apoyo dentro del mensaje argumental. Son utilizados como si de una pieza escénica se tratara: enfatizando discursos dramáticos, creando texturas dentro del escenario, contribuyendo a crear ambientes y generando dinamismo, todo siempre en favor del contexto y discurso que exige la escena que se está desarrollando. Por ejemplo, el uso de la figura de los campanilleros dentro del Rosario de la Aurora —denominados en algunos lugares «auroros», siendo en este caso hombres los que salen de procesión - viene a recordar una costumbre popular, un acto ajustado y unido a la tradición cristiana. El uso de este elemento dentro de la dramaturgia representa una escena en la que se invita a la reflexión de los actos cometidos, otorgándole un nuevo reflejo cómico dentro del contexto y discurso argumental.

\subsection{Elementos escénicos}

Entendemos por elementos escenográficos todos los componentes visuales que forman parte de una escenificación. Se incluyen aquí los decorados y la caracterización de personajes, que pasa por el maquillaje, el vestuario, la iluminación, etc.

En la representación de la versión danzada de La mujer y el pelele son varios los elementos que van a servir de soporte para ir encajando las diferentes escenas y dar así una mayor robustez argumental.

Relación de elementos principales:

-Suelo de madera como imitación de un suelo hidráulico: servirá para situarnos en un lujoso salón de una casa señorial sevillana.

-Mesa de madera a modo de escritorio o mesa de despacho donde se encuentran pequeños objetos que serán de utilidad como apoyo gráfico. Estos son: una caja de música con una pequeña bailarina, un pequeño baúl con monedas, un plumier, una cesta con frutas y verduras, etc. Todos estos elementos serán usados en diferentes momentos teatrales.

-Una jaula abierta sin pájaro en su interior: elemento utilizado de forma simbólica.

-Complementos de disfraces de carnaval: gorros, matasuegras...

-Vestuario: trajes lujosos, sombrilla, atuendo frívolo, trajes de flamenca, abrigo raído, trajes de caballero, hábito de monje, etc.

-Otros elementos: campanilla de aurora, farol, sábana. Audiovisuales: película documental de $8 \mathrm{~mm}$ de los años 70 . 
Enclaves. Revista de Literatura, Música y Artes Escénicas, n.o 1, 2021, pp. 125-143. eISSN 2792-7350

Isabel Bayón Gamero, «De la literatura a la escena. Descripción

Compañía Isabel Bayón», https://dx.doi.org/10.12795/enclaves.2021.i01.08

-Gafas de ciego, monedas, paquete de cigarrillos, atizador de chimenea, sillas de anea.

\section{Proceso de creación coreográfica}

La mujer y el pelele fue un proyecto propuesto por la directora artística y escénica Pepa Gamboa. Este fue un segundo intento, ya que la primera vez no pudo llevarse a cabo por varios motivos; en esta ocasión, sí se dieron las circunstancias idóneas para llevar a cabo su concepción de la obra.

En primer lugar, Pepa Gamboa me propuso crear la coreografía para la obra, además de participar como intérprete encarnando el papel principal femenino - Conchita-; Gamboa, junto con la propuesta, trae consigo a las personas que forman parte del equipo creativo y técnico con las que ella suele trabajar. Así pues, se cuenta para la dramaturgia con Antonio Álamo, José Manuel Gamboa para la dirección musical, para la escenografía con Antonio Marín, para el diseño de luces con Sergio Espinelli y para el diseño de vestuario con Fernando García. Para el equipo de producción se elige a la productora con la que suelo trabajar desde hace tiempo. Será El Mandaíto Producciones el que se haga cargo de toda la gestión administrativa del proyecto.

Por otra parte, para el elenco artístico — en cuanto a músicos se refiere—, soy yo la encargada de su elección. Este punto es importante por la necesaria complicidad que, a mi modo de ver, ha de existir entre músico y coreógrafo. Es por esa razón por la que escojo a artistas que, además de tener una experiencia y sensibilidad musical particular, pueden cubrir ciertas exigencias interpretativas que son necesarias para solventar los requerimientos teatrales de la producción.

\subsection{Argumentación coreográfica / Justificación de los palos flamencos}

Las coreografías que se van intercalando dentro de las escenas y que jalonan la representación responden a un criterio artístico y funcional para ser elegidas. Seguimos, en este sentido, a Adshead, Briginshaw, Hodgens y Huxley (1999) en su propuesta de interrelación de elementos como el carácter, las cualidades o el sentido y el significado para la interpretación de una coreografía específica. Primeramente, han de ser bailes que apoyen y justifiquen la acción teatral que se está desarrollando; así pues, se hace un examen anímico y argumental de la escena buscando, para ella, el maridaje musical y de danza adecuado.

-Sevillanas y villancico

Se proyectan unas imágenes contenidas en un documental hecho por la televisión japonesa, con motivo del año internacional del niño en el año 1978, en las que Isabel Bayón es protagonista. En estas imágenes aparece una serie de planos de la ciudad de Sevilla a modo de presentación. Se utilizarán para dar una visión retrospectiva del marco geográfico donde sucede la historia. El fondo musical no podía ser otro que la sevillana popular «Viva Sevilla».

Me casé con un enano

pá jartarme de reír... 
Para la escena segunda del mismo acto y como presentación del personaje principal femenino, se recurre a otra sevillana, que en este caso canta la protagonista. En ella, se presenta una Conchita descarada y sensual que, en su cante, comienza a dar muestras de la precoz naturaleza propia del prototipo de mujer fatal que traerá de cabeza a don Mateo. En ella se desgrana la sorna y el carácter manipulador de los que hace gala el personaje durante toda la obra.

Tilín Concha, Conchita, que tienes más peligro que el que lo inventó

Siguiendo la escena, se produce la copla de encuentro en el carnaval. Se trata de una adaptación de un villancico flamenco en el que se cambiará el texto para así adecuarse convenientemente a los personajes de la obra. Hay que advertir la idoneidad del marco conceptual que ofrece la fiesta de carnaval. En ella se invierten los papeles sociales que los participantes tienen en la vida diaria para adquirir otros que son admitidos temporal y excepcionalmente dentro de la mascarada festiva. La salvedad a este paréntesis temporal, en el que los cambios de roles son permitidos, la establece Conchita, ya que el papel de inocente pero resuelta fémina que sostiene delante de Mateo se revela consistente durante todo el transcurso de la historia, más allá de la licenciada por el periodo de carnaval.

\section{-La bambera}

Mocito que está en la puerta,

entre usted y me mecerá...

Lo oportuno de la utilización de este palo es refrendado por la naturaleza y función que desempeñaba el ceremonial de la bamba dentro del ámbito rural de la época: un acto asociado al rito del galanteo y seducción propio de las parejas de enamorados. Así, la lírica de origen folclórico asociada a este palo, como su carácter y trasfondo popular, respalda su uso y, por tanto, su justificación argumental.

El discurso coreográfico absorbe y transmite todo el sentido que la letra y el acto del balanceo tiene. Lejos de brusquedades en la intención y en la acción, busca la complicidad entre los personajes, acentuando con los movimientos el carácter seductor que el momento requiere. Para este ir y venir de la bamba se recurrirá al palo tal y como lo dejara recogido Pastora Pavón, por fandangos.

-Romances de ciego

La llenaba de regalos

y ella pagaba con palos...

Para entender un poco mejor la aparición del ciego, me ayudo de los autores Alberto del Campo y Rafael Cáceres, que nos dan información acerca de los romances:

Entre los cantes que más despertaron la atención de los viajeros decimonónicos, están los monótonos romances, entonados por ciegos, arrieros y otros tipos que a los románticos les parecían de lo más pintoresco. La idea de que escuchaban fragmentos de un pasado remoto donde se relataban las gestas de personajes medievales, alentaba la imaginación romántica. ¿Podía haber algo más típicamente español? (430) 
Tal y como he comentado, la aparición del personaje ciego que va contando y cantando lo sucedido tiene un sustento y base histórica. Eran los encargados de transmitir historias y hechos de toda índole. La diferencia con el estilo del romancero culto es que, en su peculiar quehacer y manifestación, tratan de trasladar de forma coloquial los sucesos propios de la época. En la dramaturgia creada por Álamo, el personaje tiene la capacidad de crear paréntesis temporales a modo de standby, en los que la acción queda latente, siendo él quien en ese momento mantiene en movimiento el discurso narrativo de la historia.

La idiosincrasia del personaje alterna entre lo cómico y lo dramático, sirviendo así para despojar en ocasiones y certificar en otras el trasfondo amargo que la historia tiene.

En las tres escenas en las que aparece, va cantando tanto los pensamientos de don Mateo, como lo visto por una especie de espectador que contempla y relata con carácter objetivo la situación en la que se encuentra el personaje. Ataviado con un abrigo raído y unas gafas oscuras, se sirve de la guitarra a modo de bastón, dando así cierto patetismo y comicidad al personaje. En estos momentos no hay ningún tipo de baile, dándose prioridad a la función puramente narrativa. En estas intervenciones el resto de acción se congela, provocando un mayor relieve que acentúa la focalización del espectador en el personaje, que no cesa en su discurso dramático.

Con este tipo de acciones, la escena cobra énfasis, creando una sucesión de paréntesis dentro de la acción general y activando el interés del espectador.

-Campanilleros de ánimas benditas

Ave María purísima, sin pecado concebida...

Como sabemos, los coros de campanilleros en Andalucía escenifican una costumbre de raíz popular. Esta práctica manifiesta una significación afiliada a uno más de los ritos religiosos practicados por laicos. En la obra, un pequeño coro de campanilleros nos viene a retratar una estampa que nos muestra una Andalucía decimonónica íntimamente relacionada con una moral que se ampara en la ética y valores religiosos.

El uso de la figura de los campanilleros, y dentro del rosario de la aurora, viene a recordar un hábito folclórico, siendo este un acto ceñido y circunscrito a la tradición cristiana. El uso de este elemento dentro de la dramaturgia representa una escena en la que se invita a la reflexión de los actos cometidos, otorgándole un nuevo reflejo cómico dentro del contexto argumental.

Las coplas que se cantaban en los rosarios son de una gran importancia para comprender la significación catequética de estos cortejos, pues recogen en breves estrofas toda la historia de la salvación, así como reflexiones doctrinales y morales en torno a la consideración de los Misterios, que, en este caso, son los misterios de las conductas de los protagonistas...

El momento sirve como contrapunto irónico a toda la trama argumental, que nos presenta a un don Mateo que prácticamente se asoma a una actitud pederasta, y a una Conchita que, ejerciendo de nínfula, pone de manifiesto tanto su procacidad, como la pobre voluntad del protagonista masculino. A pesar del mensaje transmitido a modo de advertencia, tanto la escena como la trama siguen sin solución de continuidad. 
Enclaves. Revista de Literatura, Música y Artes Escénicas, n.o 1, 2021, pp. 125-143. eISSN 2792-7350

Isabel Bayón Gamero, «De la literatura a la escena. Descripción

\section{-Caña — Polo de Tobalo — Soleá apolá}

Tú eres el diablo, romera, que me vienes a buscar...

Estos tres cantes no aparecen unidos en la obra de forma arbitraria. Se pueden abordar de manera conjunta, ya que están muy relacionados tanto en sus versiones primigenias, como en las formas modernas que de ellos nos han llegado.

Es una de las características de este cante una serie de ayeos melancólicos que funcionan a modo de estribillo que se repite al comienzo y entre las partes principales de la letra. Esta particularidad de la caña confiere al personaje de don Mateo cierto aire lastimero que acompaña su compungido estado anímico y con la eterna petición de este para conseguir los favores de Conchita.

Ahondando más en el origen de la letra de la que se acompaña el polo de Tobalo, José Manuel Gamboa afirma: «El polo de Tobalo que nos ha llegado utiliza una copla que es parte del añejo romance del conde Sol — Eres el diablo, romera-, lo que puede hablarnos de sus orígenes "morunos" y, por ende, de la caña» (458). La significación de la letra del Romance del conde Sol «eres el diablo, romera» viene a confirmar el pensamiento que el protagonista de la obra tiene sobre su amada Conchita: un personaje casi venido del infierno, dispuesto a procurarle tormento...

El más sabio se atribula, quien tiene celos no duerme...

El último de los cantes de la trilogía, la soleá apolá, se utiliza en este caso como epílogo para cerrar una suerte de cantes, teniendo para ello las cualidades de ser el que más tesitura tonal y fuerza requiere, confiriéndole por ello un mayor poder conclusivo y dramático.

En estos tres palos emparentados se aglutinan características musicales que en sí comprenden gran parte de la esencia natural del flamenco. Los tres revisten, además de la melancolía antes citada de la caña y el polo, sobriedad, profundidad, fuerza, etc. Su elección viene justificada por la rotundidad que su desarrollo musical y danzado sugiere y requiere. Vienen a representar la arrolladora fuerza que Conchita posee, contrastando con la débil voluntad de don Mateo. La coreografía se perfila con una sucesión de pasos y movimientos que, sin abandonar nunca la insinuación ni la sensualidad que el personaje manifiesta y destila continuamente, muestran el poder propio del sexo fuerte; obviamente, el de la mujer. Don Mateo asume, impotente y subyugado, la confirmación de que no puede escapar de tan poderosa y bella carcelera.

Las letras tradicionales utilizadas están escogidas para refrendar de manera verbal el pensamiento que trasiega en la cabeza del «pelele». En ellas se descubre, como en una suerte de confesión, la verdadera y terrible verdad que el enamoramiento enmascara con el maquillaje de la fascinación. Aún así, don Mateo no puede ni quiere despertar del hechizo que parece haberle privado de la voluntad.

-Seguiriya de la distancia «Al Loco Mateo...»

El corazón duro como la piedra,

tiene esta mujer... 
Mateo de Las Heras o Mateo Lasera, más conocido como el Loco Mateo, fue un cantaor jerezano de finales del XIX que ha pasado a la historia del flamenco por ser un gran seguiriyero. Su apodo, el Loco, le fue dado por ser un personaje de extremada sensibilidad y con posibles desequilibrios emocionales y temperamentales, características que probablemente influyeron en su calidad expresiva y creativa. En este caso, nos es posible hacer un juego de palabras o utilizarlo como símil comparativo, ya que se podrían extrapolar ambos personajes: el del célebre cantaor con su homónimo novelesco.

La seguiriya es un cante dramático. Sus letras nos hablan de desgracias y sufrimientos que reflejan de alguna manera la tragedia humana. Hablan de la vida y la muerte, y del dolor que transita entre ambos estados.

Este instante es especialmente significativo para comprender más profundamente la naturaleza de Conchita. Vamos por partes.

La escena viene a representar un momento importante dentro de la dramaturgia, el de mostrar a la protagonista femenina como un ser frío y calculador, alguien que no mira las consecuencias de sus actos.

Como herramienta escenográfica y para ayudar en la comprensión de las características que el personaje reviste, se utilizará de nuevo el documental utilizado al comienzo de la obra. En él aparece una niña Isabel-Conchita que juega a la gallinita ciega con otros niños. Este juego nos sirve para hacer una alegoría, un simbolismo que nos presenta a una niña que, con los ojos cerrados y dando vueltas, va en busca de una presa, no importa quién. Se usa una superposición entre la imagen proyectada en el ciclorama y la presencia real de Conchita en el escenario. Ahí, dando vueltas las dos y encerradas en un «juego de niños», en una mezcla de pasado y presente, comenzará el baile por seguiriya.

La seguiriya es un cante y un baile que encierra un extremado dramatismo. En él se combinan un ritmo en ocasiones obsesivo con unas inflexiones y cadencias musicales que le otorgan rasgos que se identifican con las más crudas emociones, rasgos que se manifiestan a través de melismas vocales que reflejan la paradójica belleza del sufrimiento y del dolor. Estas características musicales han de tener inevitablemente su reflejo en el movimiento danzado. La coreografía retrata a una Conchita autobiográfica en su profundidad. Nos da imágenes de un ser amargo en ocasiones, solitario en su esencia, que pudiera rebelarse contra su propio ser, pero que al final sale, en apariencia, indemne de su propia naturaleza destructiva.

Para este momento argumental, don Mateo se encuentra lejos, de viaje por Italia. Se propicia pues un pasaje de soledad en ambos personajes para retratar de un modo más íntimo sus perfiles. Así, don Mateo continúa buscando alivio en otras mujeres, en definitiva, imaginando la solución a su problema de inmadurez emocional no en él, sino fuera, como corresponde a un hombre que no asume sus propias inseguridades. Por otro lado, Conchita, que se dibuja cruel en su deambular, pero que pudiera después de todo mostrarse como otra víctima más, en este caso, de ella misma.

-Coplas oportunas de alegrías

A los ojitos de mi cara los tengo que castigar, porque siempre se enamoran de quien mal pago le dan... 
La acción se desarrolla en un tablao en Cádiz. Para la escena era necesario retratar el ambiente que se producía en este tipo de escenarios. Pero este retrato, además de figurativo, se muestra en la obra como un reflejo de intenciones. Se perfila un marco donde lo principal es sobrevivir no a costa de mostrar un arte flamenco nacido de la necesidad expresiva y vital que surge del artista, sino como un recurso de supervivencia que obliga a vender un arte que se adapte a las exigencias y gustos del público. Las alegrías de Cádiz tienen entre sus características la de ser un cante desenfadado, alegre y a la vez flamenco, que muestra en su exposición la esencia vital del pueblo andaluz, gaditano en este caso, realizando un proceso mágico que trata de transformar las penurias en alegrías, riéndose así de su propia desgracia.

En este caso, los músicos son los encargados de reírse no de sus propios males, sino de los ajenos. Así, más allá de hacer exclusivamente la representación de un cante y toque al uso, se manifiestan como actores que ponen en pie el retrato de los particulares personajes que se daban cita en los tablaos.

-Sevillanas del encuentro en Cádiz

Cuando veo tus ojos, digo a los míos, mira por dónde vienen mis enemigos...

Las sevillanas vuelven a servir de instrumento musical y dancístico para referirnos de nuevo a dos de los perfiles que Conchita muestra en su personalidad: uno, el de servirse de la sensualidad y coqueteo como arma de seducción; otro, para volver a mostrar su crueldad a través de la mofa premeditada hacia el género masculino, encarnado en la figura de un cuarentón que la pretende y del que abusa.

En esta ocasión, los músicos vuelven a ser una herramienta para manifestar y certificar el poder que Conchita ejerce en los hombres. Poderosa es la imagen en la que ella baila la última de las cuatro sevillanas con una esencia manifiestamente erótica, mientras todos los hombres que están en la escena le cantan a cappella, sin quitar sus ojos de encima.

La letra vuelve a manifestar la subyugación que el hombre siente ante la tentadora esencia femenina de la que Concepción Pérez es portadora. Es una escena en la que se vuelve a contribuir al dibujo que de los tablaos de la época se quiere hacer.

-Bulerías del torrotrón (Presentación del Morenito)

\author{
¡Ay, que te quiero \\ poquito y por si acaso \\ me olvidas luego!...
}

Tomás Romero Moreno, Tomasito, encarna al Morenito. Su figura dentro de la dramaturgia de Antonio Álamo sirve como elemento de venganza en una de las últimas escenas de la novela. Es el personaje que representa la debilidad de Conchita en el terreno sentimental. Con él se manifiesta la rendición de la protagonista, demostrando así, y después de todo, la «escondida humanidad» que el frío y calculador personaje de Conchita también posee. Era necesario mostrar de alguna manera la antítesis que representa don Mateo, es decir, la de alguien que no se muestra apocado, que vierte su personalidad 
provocadora y chulesca en la escena y que da muestra de la actitud canalla que sirve de imán para el modelo de mujer que representa Conchita.

La aparición de Morenito está llena de ritmo y nos muestra su carácter desinhibido y burlesco. No podría ser otro que el cante y el baile por bulerías el que nos sirviera para escenificar de manera danzada el perfil del personaje. En la escena vemos a un don Mateo atribulado y a una Conchita que, embelesada, contempla a su verdadero amante. Los tres principales personajes están perfectamente dispuestos en la escena para que el espectador no pierda en ningún momento la perspectiva de lo que sucede en el interior de cada uno de ellos.

-Tangos del «reservado»

¿No tienes miedo a nada?

¿No tienes miedo a morir?

Quizás como reminiscencia de esa diosa Astarté que los fenicios dejaran en el sur de la Península, o puede que queriendo establecer un puente gremial con las puellae gaditanae, Louÿs nos entrega a una Conchita que ejerce de bailarina, la más bella y sugerente, una Telethusa particular a los ojos de don Mateo. En la escena, Conchita se revela provocadora, mostrando su cuerpo semidesnudo a un grupo de hombres que la contemplan embriagados de lascivia... Si tuviéramos que procurar un palo flamenco que en su sentido musical y bailado contenga toda la sinuosidad y el carácter sensual y extático que un baile pudiera albergar, sería sin duda los tangos flamencos. Para iluminar un poco mejor el carácter de este baile, acudimos a José Luis Navarro, quien nos presenta alguno de los rasgos y características de los diferentes tipos de tangos de comienzos del siglo $\mathrm{XX}$ :

Comienzan entonces algunos a distinguir entre el que llaman tango gitano y tango de las vecindonas corraleras. Nos lo cuenta hacia 1912 el maestro Otero:

Fueron conocidas dos clases de tango, uno que se llamaba tango gitano, muy flamenco, y que no se podía bailar en todas partes, por las posturas, que no siempre eran lo que requería las reglas de la decencia, y el otro que le decían el tango de las vecindonas o de las corraleras, pero éste se encontraba entre mil muchachas una que se atreviera a bailarlo, aunque supiesen hacer las cuatro tonterías con que solía adornarlo la que era un poco despreocupada. (Navarro 223-224)

La escena se sucede dentro de un reservado en un tablao de Cádiz. Fue la antigua Gadir romana la que en tiempos pasados diera asiento a aquellas bailarinas que trascendieron su fama por sus particulares danzas. Vuelve a ser esta ciudad la que justifique - dentro de una perfecta ambientación de la dramaturgia - y recoja el episodio en el que don Mateo vuelve a ser seducido y reducido por la inefable Conchita. La escena vuelve a confirmar una vez más la maestría que la protagonista tiene manejando a un más que enojado Mateo, que se quiere pensar como principal titular de los sentimientos amorosos de Conchita. La coreografía ideada no abandonará en ningún momento el principal objetivo y función que tiene dentro del pasaje dramático. Su desarrollo coreográfico se alejará del sentido de baile por tangos al uso, pero sin abandonar nunca la esencia flamenca y original que este palo tiene. 
Enclaves. Revista de Literatura, Música y Artes Escénicas, n.o 1, 2021, pp. 125-143. eISSN 2792-7350

Isabel Bayón Gamero, «De la literatura a la escena. Descripción

Una vez concluidos los tangos, reaparecerá de fondo, y a modo de desenlace de escena, una música que, retomada del episodio del encuentro en el carnaval, nos recordará el carácter irónico, jocoso y manipulador que como mensaje ha de mantenerse de manera continuada.

-Tangos trianeros

Cómo has tenío el valor

de echarte un amante nuevo

estando en el mundo yo...

Es una de las escenas finales. En ella se muestra a los personajes de Conchita y del Morenito jactándose de haber arrebatado de manera consentida el dinero a don Mateo. Vuelven a ser los tangos, pero en este caso es el estilo de tangos de Triana, los que mejor captan el espíritu de lo que acontece. En una rítmica binaria de $6 / 8$ propia de los tanguillos gaditanos, son estos de Triana los que ahora transmiten la divertida y a la vez desalmada victoria de la pareja sobre el pelele. Baile sin serlo, en pareja, pero sin un planteamiento coreográfico ordenado, un acto con sentido teatral, un caos festivo que muestra la algarabía del triunfo, del logro de lo propuesto.

En una suerte de locura, son todos los personajes que hay en el escenario -músicos, cantaores, ciego- los que se benefician de la situación, entrando en casa de don Mateo y expoliando sus pertenencias. Se vuelve a mostrar el trasfondo de toda una parrilla de personajes asociados a la picaresca como estandarte de su modus vivendi.

-Baile en off por soleá

Tiro piedras por la calle, y a quien le dé que perdone

Es la vuelta a la realidad. Como recurso dramático, Gamboa y Álamo hacen uso del documental gráfico de la niña Isabel, para, a través de un baile realizado en el teatro Falla de Cádiz, hacer un guiño escénico que alterna la representación teatral que aparece en la proyección con la realidad. Con ella, se devuelve la personalidad y titularidad de Conchita a una Isabel real y contemporánea, pero no deja escapar de la ficción novelesca a un don Mateo víctima de su propia y endémica debilidad. En una suerte de moraleja, parece querer mostrarnos que el hombre siempre se verá atrapado por esa tentación primera que privó a Adán del paraíso y de la salvación:

Conchita mía, te perdono. No puedo vivir donde tú no estás. Vuelve. Te lo suplico de rodillas. Beso tus pies desnudos.

Mateo.

\subsection{Proceso coreográfico / Pautas generales}

Una vez descritas las diferentes escenas que se configuran en este montaje, la idiosincrasia y carácter propio de cada personaje, las características relativas a los diferentes palos flamencos que van a servir para hilar la dramaturgia, etc., pasaré a narrar las pautas generales de creación coreográfica que se han seguido a la hora de realizar este 
proyecto. No haré la presentación contando cómo se concibió cada coreografía, sino como una exposición más conceptual y amplia que describa lo que normalmente hago a la hora de crear un baile, y que puede definir mi forma personal de trabajo. Me centraré en lo que Graham Wallas, ya en los años veinte, planteó como base de los procesos creativos, con la última etapa planteada por Mauro Rodríguez: fases de preparación, incubación, iluminación, verificación y comunicación.

$\mathrm{El}$ «ritual de los pasos seguidos» puede entenderse como un modus operandi que personalmente utilizo a la hora de enfrentarme a un proceso creativo y a su confección coreográfica, es decir, un conjunto de acciones que realizo de manera casi mecánica cada vez que me enfrento a un proyecto artístico en la fase de preparación. Sería necesario hacer una diferenciación entre la labor de iniciar un proceso coreográfico y el hecho creativo. Para mí, el proceso creativo lleva implícita una serie de cuestiones que no necesariamente han de estar volcadas o verse reflejadas en la coreografía final en la fase de comunicación. El hecho creativo significa, por ejemplo, realizar un ejercicio de búsqueda de información sobre el tema a abordar, encontrar una referencia en modelos anteriores, ocupando la fase de incubación. Dichos modelos pueden encontrarse o pertenecer a facetas artísticas diversas, como la pintura, la poesía o el cine. En definitiva, se trata de encontrar información y antecedentes sobre los que nutrirse y buscar inspiración. Considero este paso previo de gran importancia, ya que es conveniente situarse dentro del conocimiento del tema a abordar. Eso proporcionará una visión más amplia, a la vez que concreción y mayor propiedad para abordar la cuestión en sí.

Otro punto de actuación muy importante es la transmisión y puesta en común de ideas y objetivos con el resto de partes implicadas en el proceso de iluminación. Existe un «trabajo de mesa» que hay que realizar con la dirección, con las personas encargadas de la dramaturgia, la música, la escenografía, el diseño del vestuario, etc. En este tipo de reuniones previas al trabajo de escenario, se ponen en común las diferentes visiones y perspectivas que se tienen sobre un mismo objeto de estudio. Es un camino donde se produce un intercambio de opiniones que va creando un ambiente de trabajo en el que la diversidad de ideas va enriqueciendo y haciendo crecer el proyecto sobre el que se trabaja.

En ocasiones, las ideas previas con las que cada uno de los componentes que forman parte del proyecto acude al trabajo se transmutan para convertirse en otras que se entienden más enriquecedoras y más propicias para encontrar la meta común a la que se pretende llegar, surgiendo así una verificación de la idea o solución creativa: analizarla y evaluarla para perfeccionarla y determinar su carácter idóneo o no.

Resulta obvio decir que existe un intento de todos los integrantes del proyecto de ser uno y de tener los mismos intereses y objetivos a la hora de acudir a la creación. Puede ocurrir en ocasiones que se produzca un conflicto en cuestiones artísticas; esto ocurre en virtud de posibles diferencias de opinión, pero esas incidencias son aprovechadas para volver a dar una vuelta de tuerca al hecho en cuestión y llegar a un acuerdo consensuado que mejore el resultado final.

En lo relativo al proceso coreográfico, cada coreógrafo suele atender a unas pautas propias y personales de actuación. En mi caso, intento hacer una puesta en común de varias cuestiones que creo relevantes y necesarias a la hora de crear la coreografía. Pasaré a describir dichas pautas.

1. En el momento de concebir coreográficamente un número, intento conjugar una serie de elementos que creo imprescindibles. Uno de estos elementos es tener en cuenta el carácter propio del palo a interpretar; es decir, intento imbuirme de los 
rasgos que son exclusivos de dicho cante. Para poder acometer esta tarea, es necesario tener un amplio conocimiento del género a tratar, en nuestro caso, el flamenco en sus tres facetas principales de cante, toque y baile. Se trata de una premisa muy importante, ya que en el acervo de estilos flamencos se contiene en origen una paleta muy variada de características o rasgos anímicos de una naturaleza sonora; incluso podríamos decir de una filosofía interior, que está asociada a una estética propia perteneciente a cada palo en particular.

2. Otro elemento imprescindible es la música que se crea para cada baile. Para mí, la composición musical es de suma importancia. Entiendo que el movimiento siempre ha de estar motivado y fundamentado en la música, en el sonido o incluso en la ausencia de él. El concepto sonoro musical ha de tener una serie de elementos que induzcan al movimiento desde la sensación. Creo que la acción debe tener un origen motor que ha de producirse con la simbiosis del hecho sonoro y la experimentación interior del mismo. La composición debe estar en concordancia con lo que se pretenda conseguir en el conjunto de la obra o del número concreto. Bajo mi criterio, ha de conservar los rasgos fundamentales del palo a tratar y, a su vez, estar implementado por una línea compositiva que esté dirigida hacia el interés y necesidad que el conjunto de la obra requiere.

3. Otra de las fórmulas que utilizo para la creación coreográfica es la de procurar la ambientación expresiva y comunicativa a través de la utilización de los diferentes planos del escenario, así como del dibujo en el espacio en el que incluyo la diversidad de recursos dinámicos para el movimiento. Así, intento conjugar la intención interpretativa con una propuesta estética que se adapte a la necesidad planteada a priori. También procuro que, en la sonoridad y uso rítmico de los pasos, se genere una oferta percusiva donde la diferencia de intenciones y matices tenga un protagonismo equilibrado y suficiente para provocar el interés en el espectador.

4. Importante es también el lenguaje utilizado dentro de la composición coreográfica. Intento lograr una renovación del vocabulario tradicional a través de un uso mesurado y coherente de movimientos que pertenecen a un concepto que, sin ser contemporáneo, sí es más actual.

5. Creo necesarias también la claridad de ideas y la consistencia de criterio a la hora de delimitar y perfilar la acción coreográfica. La obra de un artista ha de estar definida en cada momento de creación. Esta, evidentemente, puede y debe ser susceptible de la evolución personal del creador, que creo ha de ser permeable y estar en sintonía con las pretensiones artísticas de la obra y, por otro lado, con el contexto artístico en el que se vive.

6. Una cuestión muy importante en mi proceso coreográfico es el uso racionalizado de todos los elementos anteriormente descritos con el recurso intuitivo que, a mi entender, debe aflorar en todo artista. Dicho recurso intuitivo ha de conformarse como un elemento primordial que, unido a factores como la ductibilidad, la apertura de ideas, la empatía, etc., ha de ser procurado con el fin de ahondar en el discurso interpretativo.

7. Por último, hay un elemento que pudiera considerarse secundario, pero que en mi caso tiene una incidencia directa en el resultado obtenido. La propuesta final a la que se llega en un proceso de creación coreográfica es el fruto del trabajo de un conjunto de artistas que vierten su trabajo y que colaboran en el logro de un 
Enclaves. Revista de Literatura, Música y Artes Escénicas, n.o 1, 2021, pp. 125-143. eISSN 2792-7350

Isabel Bayón Gamero, «De la literatura a la escena. Descripción

resultado último. Es por eso que han de conjugarse en equilibrio una serie de valores personales y artísticos para que pueda alcanzarse una sintonía que propicie un buen trabajo y, posiblemente, un buen resultado.

\section{Reflexión a posteriori}

Para finalizar este texto me gustaría destacar la oportuna necesidad de que el artista sea observador de sus procesos creativos, de las maneras de afrontar una nueva creación, de contemplar las normas de actuación seguidas. Un continuo cuestionamiento de lo realizado, creo, es una actitud que nos puede ayudar a entendernos mejor, invitándonos a pretender la evolución personal y artística. Por otro lado, sirve para advertirnos y tomar conciencia del papel que como actores y agentes culturales tenemos dentro de la sociedad.

El flamenco es un lenguaje único, poderoso, que no necesita excusa para ser utilizado como vehículo de transmisión de emociones e ideas. Pero creo que tenemos la oportunidad de acompañar el desempeño de nuestro papel dentro del flamenco con un rigor que venga definido por un plan de actuación respaldado por la investigación, la comunión de elementos e ideas, la integración de nuevos conocimientos, la autocrítica, el respeto hacia la tradición y, cómo no, la apertura a la experimentación y, con ella, a lo bueno que esté por llegar. El flamenco, desde su origen, fue una disciplina fruto de mixturas y contagios, a lo que se le ha sabido añadir la verdad personal de sus intérpretes dentro de un marco único, genuino y heterodoxo.

\section{Referencias}

Adshead, Janet et al. Teoría y práctica del análisis coreográfico. Valencia: Federación Española de Profesionales de la Danza. Ministerio de Educación y Cultura, 1999.

Del Campo, Alberto y Rafael Cáceres. Historia cultural del flamenco. El barbero y la guitarra. Córdoba: Editorial Almuzara, 2013.

Gamboa, José Manuel. Una historia del flamenco. Barcelona: Espasa Libros. S. L. U., 2011.

Goujon, Jean-Paul y María del Carmen Camero. Pierre Louÿs y Andalucía: cartas inéditas y fragmentos. Sevilla: Ediciones Alfar, col. Alfar/Universidad n. ${ }^{\circ} 8,1984$.

Louÿs, Pierre. La mujer y el pelele. Barcelona: Círculo de Lectores, 1985.

Navarro, José Luis. Breve historia ilustrada del Baile Flamenco. Sevilla: Libros con Duende. S. L., 1995.

Pavis, Patrice. El análisis de los espectáculos: teatro, mimo, danza, cine. Barcelona: Paidós Ibérica, 2000.

Rodríguez, Mauro. Creatividad en la investigación científica. México: Trillas, 1991.

Valle-Inclán, Ramón M. ${ }^{a}$ del. La cara de Dios. Madrid: Taurus, 1972.

Wallas, Graham. The Art of Thought. The Model of Creativity. Tunbridge Wells: Solis Press, 2014 (or. 1926).

Enlace a extracto del espectáculo:

https://www.youtube.com/watch?v=uyCaGwQ0yYk 